\title{
Case Report: Gestational Gigantomastia
}

Tamayo Carbon AM1, Vila Garcia $\mathrm{E}^{2 *}$, Cuastumal Figueroa $\mathrm{DK}^{3}$ and Vargas Mendez $\mathrm{MI}^{4}$

${ }^{1}$ Specialists of II degree in Plastic Surgery and Caumatology, Surgical Hospital Hermanos Ameijeiras, Cuba

${ }^{2}$ Specialist I degree in General Surgery, Surgical Hospital Hermanos Ameijeiras, Cuba

${ }^{3}$ 2nd Year Resident of Plastic Surgery and Caumatology, Surgical Hospital Hermanos Ameijeiras, Cuba

${ }^{4}$ 2nd Year Resident of Plastic Surgery and Caumatology, Surgical Hospital Hermanos Ameijeiras, Cuba

*Corresponding author: Eyleen Vila Garcia, Assistant Professor, Services of General Surgery and Plastic Surgery, Surgical Hospital Hermanos Ameijeiras, Havana City, Cuba, Tel: 53232327; Email: hielenvg@infomed.sld.cu

\section{Abstract}

Introduction: Gestational gigantomastia is the increase in breast tissue during pregnancy greater than $1500 \mathrm{ml}$ of volume in each breast. It is known that it can have harmful effects on both the fetus and the mother. The surgical treatment of choice is reduction mastoplasty.

Method: We describe a patient with a history of gestational gigantomastia who underwent reduction mastoplasty using the Thorek technique.

Result: A 23-year-old patient is presented with a diagnosis of gestational gigantomastia who underwent a reduction mastoplasty. $1200 \mathrm{~g}$ of breast tissue were resected from the left breast and $1300 \mathrm{~g}$ from the right breast. The postoperative evolution of her was favorable with good aesthetic and emotional results.

Conclusions: Reduction mastoplasty using the Thorek technique is the surgical technique of choice for gestational breast hypertrophy because it allows a great reduction in breast volume with good aesthetic results and patient satisfaction.

Keywords: Breast hypertrophy; Gestational gigantomastia; Thorek technique

\section{Introduction}

The breasts are female organs of great importance, a symbol of sexuality, beauty, an emblem of motherhood and an erogenous zone par excellence. In all times they play a very important role in female body image [1].

Breast hypertrophy is a medical condition that is characterized by the excessive development of the mammary gland with more than $50 \%$ of the normal or ideal volume. Consequently, it is a common cause of physical and emotional suffering. The clinical manifestations are diverse and vary from local, regional, to systemic symptoms. The most frequent local symptoms are infection and inflammation; while the regional ones are osteomyoarticular pain, thoracic deformity and nerve compression. In addition, psychological disorders of body dysmorphia occur due to a decrease in the self-esteem of patients [2].

Depending on the breast volume, it can be classified into mild breast hypertrophy up to $300 \mathrm{~g}$, moderate from 300 to $700 \mathrm{~g}$, large from 700 to $1200 \mathrm{~g}$ and gigantomastia when the volume is greater than $1200 \mathrm{~g}[2,3]$. The etiology of gigantomastia is related to genetic, hereditary, ethnic, 


\section{International Journal of Transplantation \& Plastic Surgery}

hormonal, nutritional factors, or associated diseases such as obesity [3].

Sometimes the increase in breast tissue becomes abnormally excessive and disabling during pregnancy, known as gestational gigantomastia. This medical condition can have harmful effects on both the fetus and the mother, which is why in most cases induction of labor is performed [4].

The treatment of choice for gigantomastia is surgical using the reduction mastoplasty technique. This allows reducing the skin of the breast, the volume, the weight and lifting all the breast tissue [5]. In 1922 Thorek described the technique of reductive mastoplasty that consists of radical resection of the breasts and transplantation of the Areola Nipple Complex (ANC). Since then, this procedure has remained in force and its indication is only in patients with gigantomastia who require a free transplantation of the ANC to achieve satisfactory aesthetic results $[6,7]$. However, this technique is seldom used due to its mutilating effect on breastfeeding and the impairment of the sensitivity of the ANC. This is because it resects large amounts of breast tissue through the cross section of the milk ducts and removes the entire areola. That is why this patient is presented with the aim of showing that this technique is the best surgical option for the treatment of gestational gigantomastia $[8,9]$.

\section{Case Report}

23-year-old white female patient with a history of exaggerated breast enlargement during her pregnancy. She is being evaluated by endocrinology and hyperprolactinemia is diagnosed, for which she is prescribed Cabergoline plus Bromocriptine. She did not have clinical improvement with medical treatment, for which she is referred to the Plastic Surgery service for surgical treatment. She has a gynecoobstetric history of menarche at 10 years, menstrual formula $5 / 28$, searched 16 years, no use of contraceptives, primiparous and denies a family pathological history.

On questioning, she referred to an exaggerated increase in the volume of the breasts with intertrigo in the Submammary Groove (SG) fold from the 20th week of gestation. Then, at 34.1 weeks of gestation, permanent deformity of the breasts, pain in the cervical, thoracic and lumbar spine, difficulty sleeping, respiratory difficulty and vertigo appeared; so a cesarean section was indicated (Figure 1).

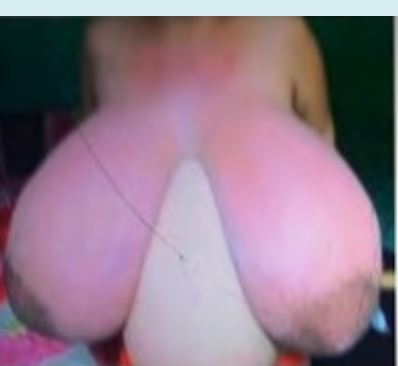

A

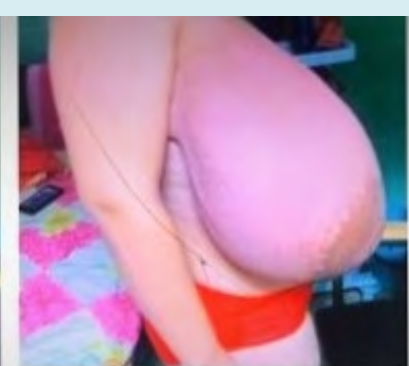

B

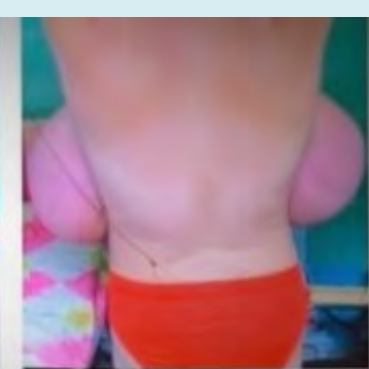

C

Figure 1: Pregnant women of 34.1 weeks. A: Front view, B: Side view; C: Back view.

Consequently, she presented dissatisfaction with the appearance of her breasts, associated with postural pain and the inability to perform routine activities, including walking.

Physical examination revealed a thorax with a tendency to excavate in the anterior region in relation to position, shoulders projected forward, posterior thorax with mild kyphosis. Enlarged breasts, ptosic, of moderate base, separated at the sternal level, asymmetric, the right breast being slightly larger than the left, low implantation, right divergence, left convergence and axillary projection. Nipples without alterations in number or shape, without bleeding or discharge. It is observed that the ANC exceeds the SG by approximately $10 \mathrm{~cm}$. Slight hypochromic enlarged vergetures predominantly in the upper quadrants, hyperpigmented lesions in both SG with mild erythema and heat. On palpation, there is slight generalized pain on palpation of both breasts, without evidence of tumor lesions, nipple discharge, or axillary lymphadenopathy (Figure 2) (Table1).

\begin{tabular}{|c|c|c|}
\hline Distances & Right Breast & Left Breast \\
\hline Fork - ANC & $41 \mathrm{~cm}$ & $39 \mathrm{~cm}$ \\
\hline ANC & $17 \times 15 \mathrm{~cm}$ & $16 \times 16 \mathrm{~cm}$ \\
\hline SG - ANC & $26 \mathrm{~cm}$ & $22.5 \mathrm{~cm}$ \\
\hline ANC - Umbilicus & $8 \mathrm{~cm}$ & $7 \mathrm{~cm}$ \\
\hline Volumen & $1900 \mathrm{gr}$ & $1800 \mathrm{gr}$ \\
\hline InterANC & $15 \mathrm{~cm}$ & \\
\hline
\end{tabular}

Table 1: Measurements of the breasts. 


\section{International Journal of Transplantation \& Plastic Surgery}
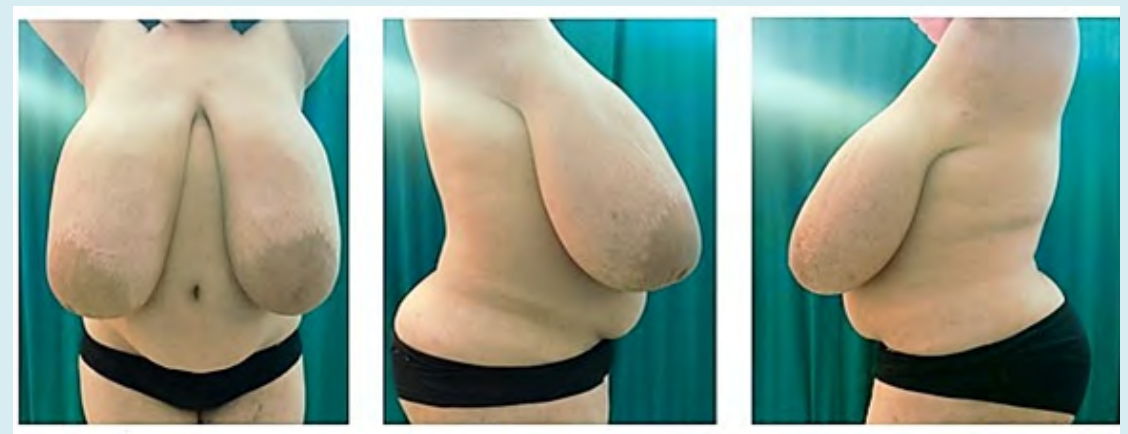

Figure 2: Gestational gigatiomastia. Preoperative Period. A: Front View. B: Right side view C: Left side view

COVID-19 rapid test paraclinical examinations were performed: negative, complete blood count within normal parameters. Post-treatment prolactin dosing was performed which was normal. With all these elements, gestational gigantomastia is diagnosed and surgical treatment is proposed. The technique of choice is the Thorek reduction mastoplasty, which consists of radical resection of both breasts with a lower pedicle flap and a free ANC graft.

\section{Surgical Technique}

The first thing that is done in the operating room is the planning of the flaps. The patient is then placed in a supine position, asepsis, antisepsis, and sterile field drapes are placed. Under general orotracheal anesthesia, a skin incision is made according to planning, the ANC is excised as a free total skin graft and it is kept protected with compresses moistened in saline solution (Figure 3).

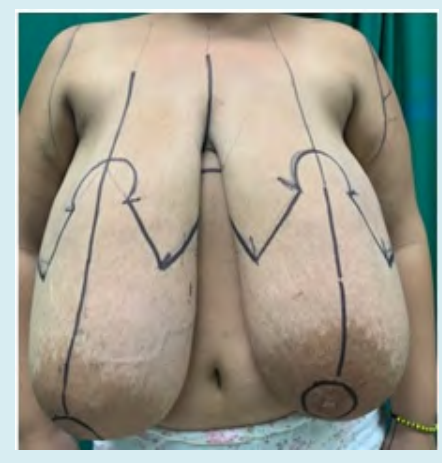

Figure 3: Preoperative planning front view.

According to the Schwartzman maneuver, the lower base pedicle flap is de-epithelialized and dissected to the pectoral fascia. Excess dermoglandular tissue is resected. The inferior pedicle flap is fixed to the pectoral fascia with a 3-0 no absorbable suture to create containment and projection of the breast, as well as to prevent future flattening. The lateral pedicles are sutured, after rigorous hemostasis and placement of suction drains, closure is continued by planes until the skin ending with an inverted " $\mathrm{T}$ " closure with nonabsorbable suture. The ANC is grafted using Brown fixation, sterile dressings are placed, and the breasts are immobilized with an elastic bandage without exerting pressure. The postoperative evolution was favorable. The graft is discovered on the fifth day and had a $100 \%$ survival. No complications are reported (Figure 4).

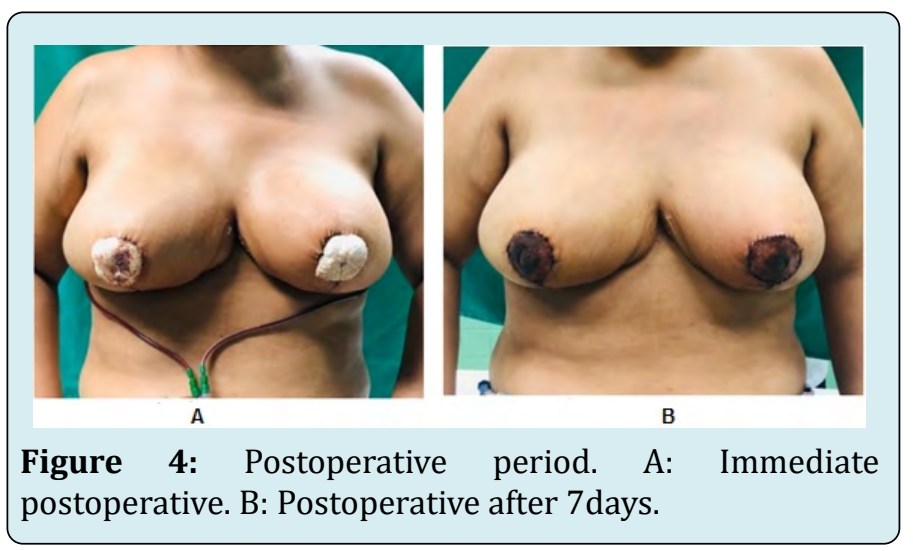

\section{Discussion}

Reduction mastoplasty is a surgical procedure that has general or technique-specific surgical risks and complications [10]. In the presented patient, there is agreement with the literature regarding the age of diagnosis. Pena Vicente [11], registered an average of 38 years with extreme ages between 15 and 56 years. Like Yepez Intriago $\mathrm{M}$ [12] in her study, where she describes patients with ages ranging between 16 and 70 years, with the group that most requested this procedure between 20 and 30 years. Sanchez Castillo VM [13] published an article on minimal incisions for reducing mastoplasties, where ages between 30 and 39 years old, and extreme ages between 15 and 59 years predominated. The maximum breast volume recorded in the preoperative period was greater than $1500 \mathrm{gr}$, with a greater increase in the right breast, which differs from Grippaudo FR, [14] in their study carried out in 2009 where the cases studied showed greater growth of the left breast. In the postoperative period, likewise, breast symmetry with conical 


\section{International Journal of Transplantation \& Plastic Surgery}

shape and adequate projection according to its biotype and characteristics of the thoracic region. Post-surgical measurements were within the parameters established for an ideal breast. The resected breast volume was $1200 \mathrm{~g}$ in the left breast and $1300 \mathrm{~g}$ in the right. The technique used allows the amount of tissue to be resected to be predetermined from planning. The most frequent complications reported in the literature for reduction mastoplasty techniques in large breast hypertrophy vary from seromas, hematomas, suture dehiscence to different necroses (total or partial ANC, total or partial flap, steatonecrosis). In the study carried out by Fonseca 15 in 371 patients, large volumes of breast tissue were resected, with an average of 870 grams for each breast and complications occurred in $11.4 \%$, the most common being wound dehiscence at the junction of the breast $\mathrm{T}$ in $4.6 \%$ and all wounds closed by second intention. Unlike the case presented, it did not have any complications [15].

The operated patient presented total satisfaction. The remission of the general, regional and local postoperative symptoms (respiratory restriction, radiculitis, grooves in the shoulders, intertrigo and cervicothoracic pain) was verified, achieving their incorporation into social, work and partner life.

\section{Conclusion}

Reduction mastoplasty using the Thorek technique is the surgical technique of choice for gestational breast hypertrophy because it allows a large reduction in breast volume with good aesthetic results and patient satisfaction.

\section{References}

1. Alviar Rueda JD (2018) benign breast disease: diagnosis and treatment. Med Uis 31(3): 61-71.

2. Jimenez Reyes W, Rodriguez Gil E, Jiménez Reyes W (2018) Reductive mastoplasty by modified Thorek technique in gigantomastia. Rev Inform Cient 97(1): 183-191.

3. Pitanguy I, Radwanski HN (2016) Correction of breast hypertrophy and hypomastia. In: Coiffman F. Coiffman. Reconstructive and aesthetic plastic surgery. $4^{\text {th }}$ (Edn.), Bogota: Amolca, pp: 1857-1868.

4. Perez Panzano E, Gascon Catalan A, Sousa Dominguez $\mathrm{R}$, Carrera Las Fuentes P, Javier García-Campayo, et al. (2017) Reduction mammaplasty improves levels of anxiety, depression and body image satisfaction in patients with symptomatic macromastia in the short and long term. Psychosom Obstet Gynaecol 38(4): 268-275.

5. Hojman J, Vinicki JP, Gonzalez CN, Dubinsky D, Nasswetter G (2015) Gestational Gigantomastia in Autoinmune Diseases. J of Clinical Rheumatology 21(2): 110-112.

6. Min Jeng C, Jung Hyun Y, Hyeon Gon C, Wan Seop K, Yeong Beom Y, et al. (2015) An idiopathic gigantomastia. Annals of Surgical Treatment and Research 88(3): 166169.

7. Traore B, Kamate B, Conde M, Keita A, Kourouma T, et al. (2015) An exceptional case of bilateral gestational gigantomastia with multiple breast lumps. Pan African Medical J 20: 309.

8. Bellini Ditta L (2018) Breast ptosis and surgical resolution. Argentine Journal of Plastic Surgery 24(2): 95-104.

9. Berrocal Revueltas M (2014) The four seasons of the breasts. $1^{\text {st }}$ (Edn.), Bogota: Medical Printing, pp: 25-26.

10. Agbenorku P (2006) Nipple-areolar complex (NAC) composite grafts in the management of macromastia: review of complications. Nigerian J Surg Res 8(1): 86-89.

11. Pena Vicente S, Gonzalez Peirona E, Güemes Sanchez A, Sousa Dominguez R, Garcia Campayo J (2003) Reduction mammoplasty: surgery for a psychosocial problem. Senol Patol Mamaria 16: 53-57.

12. Yepez Intriago M, Estrella Tejada P, Velez Polit E (2013) Reduction mammoplasty with small scars for large breast hypertrophy or gigantomastia. Cir Plast Iberolatinoam 39: $1-8$

13. Sanchez Castillo VM, Collado Hernandez CM (2002) Minimal incisions for reducing mastoplasties. Rev Cub Cir 41: 11-15.

14. Grippaudo FR, Kennedy DC, Tiwari P, Talavera F, Shenaq SM, et al. (2020) Liposuction only breast Reduction. Medscape Plastic Surgery \& Aesthetic Medicine.

15. Fonseca CC, Veiga DF, Garcia EDS, Cabral IV, de Carvalho MM, et al. (2018) Breast hypertrophy, reduction mammaplasty, and body image. Aesthet Surg J 38(9): 972-979. 